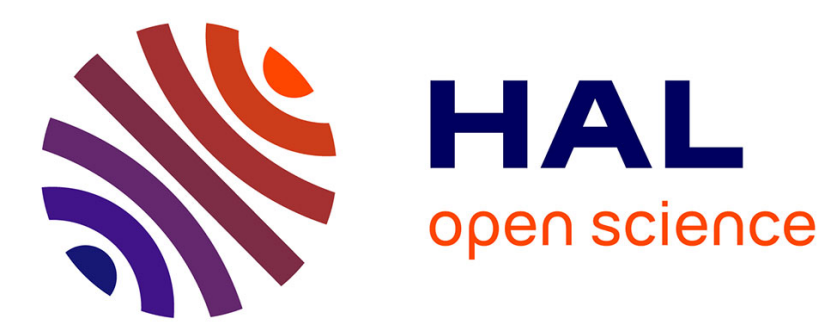

\title{
Properties of a HfC-Reinforced Nickel-Based Superalloy in Creep and Oxidation at $1100^{\circ} \mathrm{C}$
}

\author{
Elodie Conrath, Patrice Berthod
}

\section{To cite this version:}

Elodie Conrath, Patrice Berthod. Properties of a HfC-Reinforced Nickel-Based Superalloy in Creep and Oxidation at $1100^{\circ} \mathrm{C}$. Materials Science, 2018, 53 (6), pp.861-867. 10.1007/s11003-018-0146-7 . hal-02566604

\section{HAL Id: hal-02566604 https://hal.science/hal-02566604}

Submitted on 7 May 2020

HAL is a multi-disciplinary open access archive for the deposit and dissemination of scientific research documents, whether they are published or not. The documents may come from teaching and research institutions in France or abroad, or from public or private research centers.
L'archive ouverte pluridisciplinaire HAL, est destinée au dépôt et à la diffusion de documents scientifiques de niveau recherche, publiés ou non, émanant des établissements d'enseignement et de recherche français ou étrangers, des laboratoires publics ou privés. 


\title{
PROPERTIES OF A HFC-REINFORCED NICKEL-BASED SUPERALLOY IN CREEP AND OXIDATION AT $1100^{\circ} \mathrm{C}$
}

\author{
Elodie Conrath and Patrice Berthod
}

\author{
Institut Jean Lamour (UMR CNRS 7198), University of Lorraine, B.P. 70239, 54506 Vandoeuvre-lès-Nancy, \\ France \\ E-mail : pberthodcentralelille1987@orange.fr
}

\begin{abstract}
A cast Ni-based superalloy strengthened by hafnium carbides was cast and characterized at $1100^{\circ} \mathrm{C}$ in creep and in hot oxidation. The as-cast microstructure, composed of a dendritic matrix and of eutectic script-like HfC carbides imbricated with matrix in the interdendritic spaces, is very favorable for high mechanic properties at high temperature. This was confirmed by a three-point flexural creep test carried out at $1100^{\circ} \mathrm{C}$ under $20 \mathrm{MPa}$. The slow parabolic mass gain kinetic showed that this alloy is very resistant against oxidation at $1100^{\circ} \mathrm{C}$ in air. The $\mathrm{HfC}$ carbides remained stable during these tests. The oxidation behavior was chromia-forming. This alloy appeared ready to be used for structural applications at a temperature reachable by only $\gamma / \gamma^{\prime} \mathrm{Ni}$ based single-crystals or ODS superalloys.
\end{abstract}

Keywords: Ni alloy, HfC carbides, creep resistance, high temperature oxidation.

Post-print version of the article Materials Science, Vol. 53, Nº6, May 2018; pp. $861-867$. DOI: $10.1007 / \mathrm{s} 11003-018-0146-7$

In front of the demand of superalloys for applications at increasing temperatures the microstructure solutions begin lacking to offer a complete set of good properties at high temperature (H.T.): toughness, mechanical strength, good behavior in hot oxidation and corrosion, and furthermore workability with complex shapes [1]. Obtaining coarse grains for high temperature strength by keeping complex shape feasibility leads to casting process. The obtained microstructures are necessarily polycrystalline. The presence of grain boundaries and, consequently of intergranular reinforcing particles (e.g. carbides), limit the fusion start temperatures. This does not allow applying optimized heat treatments to achieve high mechanical strength at very high temperature such as the high volume fractions of $\mathrm{Ni}_{3} \mathrm{Al}$ precipitates in $\mathrm{Ni}$ based $\gamma / \gamma$ 'single-crystals.

MC carbides are among the most efficient particles for strengthening grain boundaries. The most common $\mathrm{MC}$ carbides are the tantalum carbides. The script-like shape of $\mathrm{TaC}$ in cast Co-based alloys are very useful for resisting creep at H.T. Unfortunately they are not so stable in Ni-based alloys [2]. Hafnium carbides are other possible MC which may precipitate in Co-based alloys with the same morphology as $\mathrm{TaC}$ [3]. This second type of $\mathrm{MC}$ carbide is also script-like and very stable at H.T. in Co-based [4].

Combining a Ni-based matrix rich in $\mathrm{Cr}$ and $\mathrm{HfC}$ carbides in a cast alloy may is an interesting solution for constituting complex-shaped pieces resisting both chemical aggressiveness from gases and melts (intrinsic property of a Ni-Cr base) and mechanical solicitations (austenitic network of Ni matrix and interdendritic reinforcement by $\mathrm{HfC}$ ), at H.T. This is what was attempted in this work with a $\mathrm{Ni}-25 \mathrm{Cr}-$ $0.25 \mathrm{C}-3.7 \mathrm{Hf}$ alloy.

\section{Method of investigation}

$40 \mathrm{~g}$ of this alloy, named "NCCHf", was cast from pure elements (Alfa Aesar, > 99.9 wt.\%), in the water-cooled copper crucible of a High Frequency Induction furnace (CELES), under 300 mbars of pure Ar. A Ni(bal.)-25Cr-0.25C alloy, named "NCC", was added to the study in order to specify the effect of Hf on the oxidation behavior. This second alloy was elaborated in the same conditions as NCCHf.

Three types of samples were prepared. A first compact one was kept for the metallographic study of the as-cast microstructure of NCCHf. A second sample, an elongated parallelepiped, was devoted to 
creep bending tests. A third one, a square-based parallelepiped, was destined to oxidation test in thermobalance. A sample for oxidation test was prepared from NCC (reference), as base of comparison.

The metallographic sample was embedded then ground with 250 to 1200-grit SiC papers. Thereafter it was polished with $1 \mu \mathrm{m}$ hard particles for obtaining a mirror-like state. The creep sample $(1 \mathrm{~mm} \times 2 \mathrm{~mm} \times 15 \mathrm{~mm})$, was cut then polished with papers up to 1200 -grit with final strips in the length direction. This parallelepiped, with homogeneous thickness and width (tolerance: $\pm 0.01 \mathrm{~mm}$ ), was thoroughly examined by microscopy to be sure of the absence of any defects able to weaken it. The dimensions of the samples for H.T. oxidation tests were $8 \mathrm{~mm} \times 8 \mathrm{~mm} \times 3 \mathrm{~mm}$. They were polished with 1200 -grit $\mathrm{SiC}$ papers with smoothing of edges and corners.

The metallographic samples were observed using a Scanning Electron Microscope (SEM, JEOL JSM6010LA). Observations were done under 20kV in the Back Scattered Electrons (BSE) mode, with the $\times 125,250,500$ and 1000 magnifications. The obtained chemical composition was measured using the Energy Dispersive Spectrometry (EDS) device attached to the SEM. The different phases were specified by EDS spot analyses. Indentations were carried out for the two alloys using a Testwell Wolpert apparatus, to measure their Vickers hardness under a $30 \mathrm{~kg}$ load. In each case three indentations were performed; average value and standard deviation values were calculated.

NCCHf was submitted to bending tests at $1100^{\circ} \mathrm{C}$ under constant load, according to the symmetrical three point flexural method, using a dilatometer (SETARAM TMA92-16.18) modified to allow 3-points flexural testing. The space between the two bottom supports was $12 \mathrm{~mm}$ and the maximal possible deformation was about $1.4 \mathrm{~mm}$ (height of these supports). The load was applied to the sample by the upper support, inducing a 20MPa tensile stress in the middle of the bottom side of the sample. Its value was calculated for each sample by taking into account the exact values of their thickness and width. The load was progressively applied at room temperature, until the vised value. The heating was then done, at a constant rate of $20^{\circ} \mathrm{C} \mathrm{min}^{-1}$. The isothermal stage was more or less long, depending on the behavior of the tested sample. The downward vertical displacement of the upper support was recorded every 60 seconds. At the end of the experiment a cooling was applied at a rate of $-20^{\circ} \mathrm{C} \mathrm{min}^{-1}$.

NCCHf and NCC were both tested in oxidation at $1100^{\circ} \mathrm{C}$ during $46 \mathrm{~h}$, using a thermo-balance (SETARAM TG-92), in dry synthetic air. The heating was achieved at $20^{\circ} \mathrm{C} \mathrm{min}^{-1}$, and the post-isothermal stage cooling was done at $-5^{\circ} \mathrm{C} \mathrm{min}^{-1}$. X-ray diffraction (XRD) was carried out to characterize the oxides scales. The oxidized samples were thereafter covered by a thin gold coating then by a thick electrolytic nickel coating, to protect the oxide scales during cutting. The coated oxidized samples were cut, embedded and polished. They were examined using the SEM in BSE mode. The sub-surfaces and the oxide scales were subjected to spot EDS analysis.

\section{Results and discussion}

EDS analyses showed that the vised chemical compositions were well obtained. The NCCHf microstructure is illustrated in Fig. 1 (left: general view; right: details). HfC is obviously the single carbide phase present. This demonstrates that $\mathrm{Hf}$ is a much more carbide-former element than $\mathrm{Cr}$ in nickel alloys while this was the contrary for Ta in the same base (Ta less carbide-former than $\mathrm{Cr}$ in nickel alloys [2]). All the $\mathrm{Hf}$ atoms are present as $\mathrm{HfC}$ since no $\mathrm{Hf}$ was detected in the matrix by EDS. Thanks to the atomic ratio $\mathrm{Hf} / \mathrm{C}$ equal to 1 obtained by choosing $0.25 \mathrm{wt} . \% \mathrm{C}$ and $3.7 \mathrm{wt} . \% \mathrm{Hf}$, all the $\mathrm{C}$ atoms were also involved in HfC. HfC are script-like shaped and located in the interdendritic areas where they form a eutectic with the matrix, which let think to high mechanical properties at H.T. The Vickers indentations led to $194 \pm 9 \mathrm{Hv}_{30 \mathrm{~kg}}$ for NCCHf, i.e. higher than NCC $\left(163 \pm 3 \mathrm{Hv}_{30 \mathrm{~kg}}\right)$. This hardness close to 200 let expecting respectable strength at high temperature. 


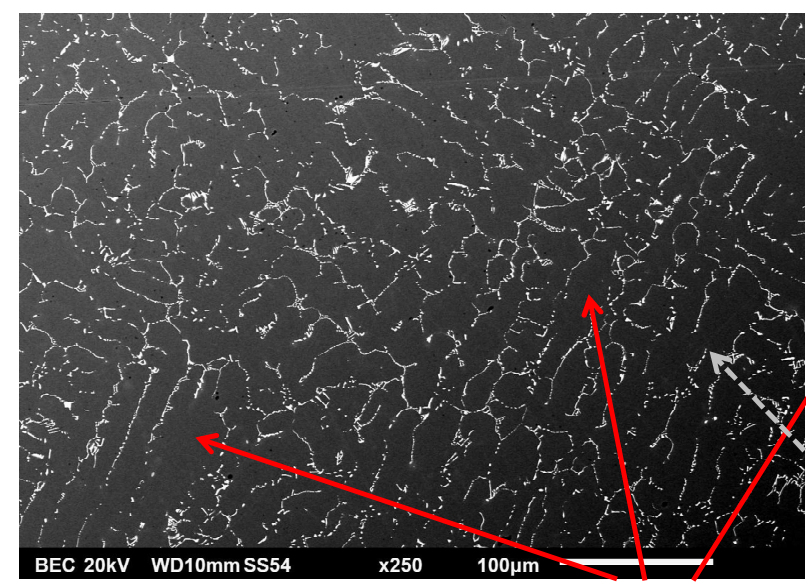

$\mathrm{M}$

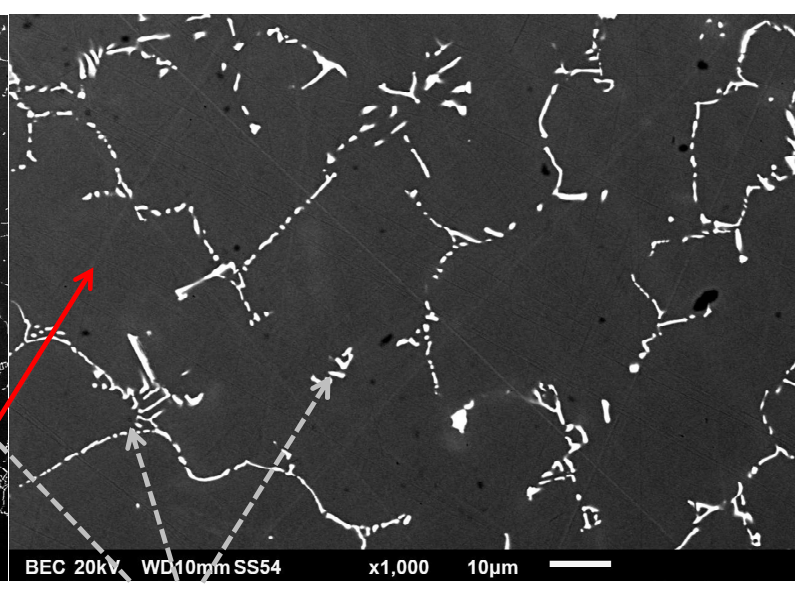

$\mathrm{HfC}$

Fig. 1. As-cast microstructure of NCCHf (SEM/BSE mode); visualization of matrix ("M") and the HfC carbides ("HfC")

The deformation curve (displacement of the upper support) obtained for NCCHf during the flexural 3-point creep test is shown in Fig. 2 together with a scanned view of the deformed sample. The deformation rate in the secondary creep stage is of only $2 \mu \mathrm{m} \mathrm{h}^{-1}$ which is very low for a nickel alloy at this temperature for a resulting tensile stress of $20 \mathrm{MPa}$.

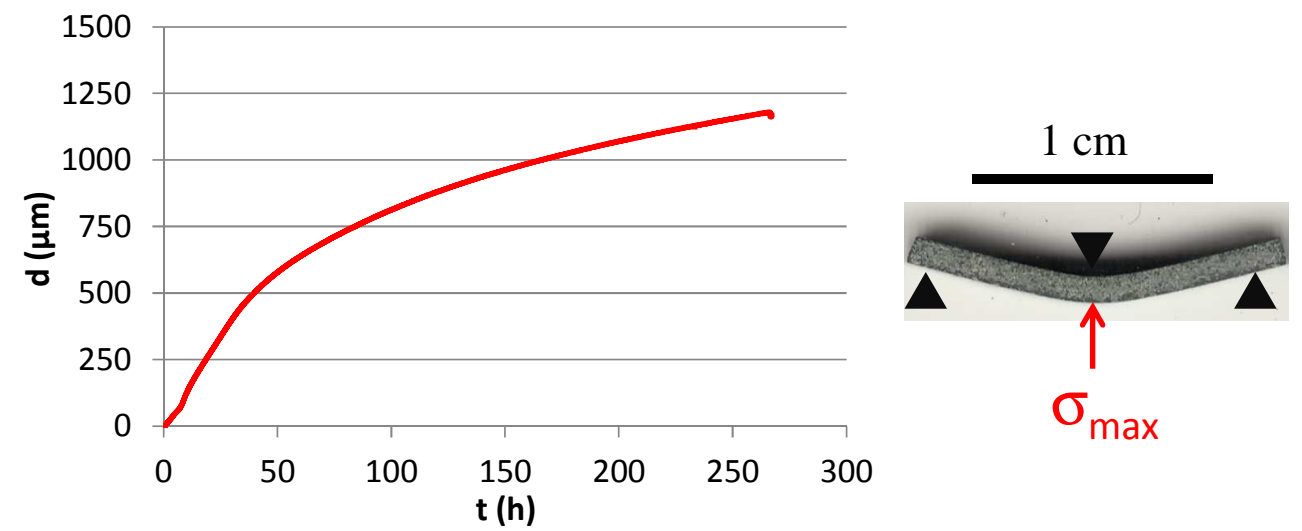

Fig. 2. Flexural creep deformation of the NCCHf alloy at $1100^{\circ} \mathrm{C}$ under $20 \mathrm{MPa}$ (" $\sigma_{\max }$ ")

The thermogravimetry test carried out at $1100^{\circ} \mathrm{C}$ in synthetic dry air led to a parabolic mass gain kinetic (Fig. 3). Compared with the mass gain curve obtained for the reference NCC alloy - the good behavior of which is well-known (among the best chromia-forming alloys in this field) - this result is very interesting. Indeed, NCCHf did not present any mass gain jump (better adherence of the oxide scale on the substrate, due to $\mathrm{Hf}$ ) and its mass gain rate is lower (Table 1). The transitory linear constant $\mathrm{K}_{1}$ (slope of the mass gain curve at the beginning of the isothermal stage) and the parabolic constant Kp classically determined (slope of the mass gain curve when plotted versus the square root of time) are effectively a little lower than for NCC (Table 1, $2^{\text {nd }}$ and $3^{\text {rd }}$ columns): 14 against $18 \times 10^{-8} \mathrm{~g} \mathrm{~cm}^{-2} \mathrm{~s}^{-1}$, and 4 against $6 \times 10^{-12} \mathrm{~g}^{2}$ $\mathrm{cm}^{-4} \mathrm{~s}^{-1}$, respectively. The comparison was also done by taking into account the mass loss by chromia volatilization (small loss of $\mathrm{Cr}_{2} \mathrm{O}_{3}$ by re-oxidation in volatile $\mathrm{CrO}_{3}$ ). For that the mass gain files were plotted according to the $\{\mathrm{m} \times(\mathrm{dm} / \mathrm{dt})=\mathrm{f}(-\mathrm{m})\}$-method [5] which allows the determination of the volatilization constant $\mathrm{Kv}(\mathrm{Kv}$ is the slope of the obtained straight line) and of the real parabolic constant $\mathrm{Kp}$ (ordinate at the origin of this same straight line) since corrected from the minimization of mass gain induced by the volatilization of chromia. The volatilization-corrected $\mathrm{Kp}$ is again slightly lower for NCCHf than for NCC $\left(12\right.$ against $\left.14 \times 10^{-12} \mathrm{~g}^{2} \mathrm{~cm}^{-4} \mathrm{~s}^{-1}\right)$. In contrast the volatilization rate seems a little higher for NCCHf ( 87 against $82 \times 10^{-10} \mathrm{~g} \mathrm{~cm}^{-2} \mathrm{~s}^{-1}$ ). 

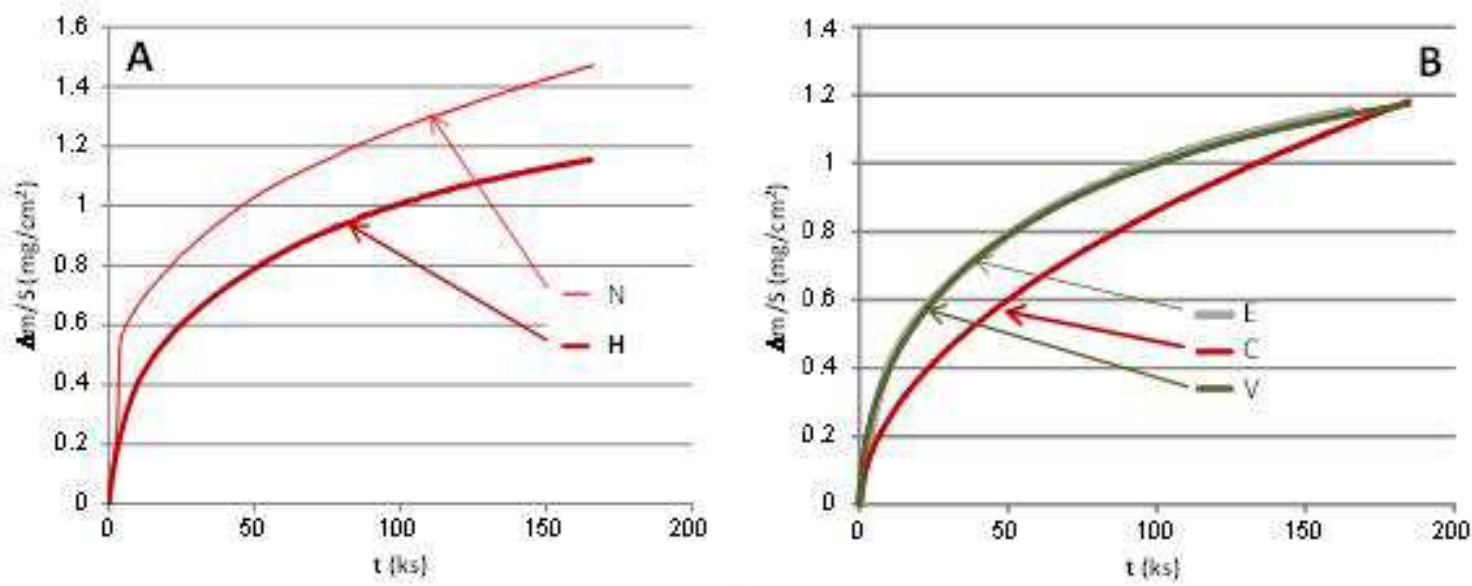

Fig. 3. A: comparison of the mass gain curves of NCCHf ("H") to the reference NCC ("N"); B: test of the determined kinetic constants by comparison between the experimental mass gain curve ("E") and the mathematical curves plotted from the Kp values either classically determined ("C") or determined according to the Kp-Kv method ("V") [5]

Table 1. Values of the oxidation kinetic constants

\begin{tabular}{|c|c|c|c|c|}
\hline Constants & $\begin{array}{c}\mathrm{K}_{\mathrm{I}} \\
\left(\times 10^{-8} \mathrm{~g} / \mathrm{cm}^{2} / \mathrm{s}\right)\end{array}$ & \multicolumn{2}{|c|}{$\begin{array}{c}K_{p} \\
\left(\times 10^{-12} \mathrm{~g}^{2} \mathrm{~cm}^{-4} \mathrm{~s}^{-1}\right)\end{array}$} & $\begin{array}{c}K_{v} \\
\left(\times 10^{-10} \mathrm{~g} / \mathrm{cm}^{2} / \mathrm{s}\right)\end{array}$ \\
\hline Alloys & slope at stage start & classic & $\mathrm{m} \times \mathrm{dm} / \mathrm{dt}=\mathrm{f}(-\mathrm{m})$ & $\mathrm{m} \times \mathrm{dm} / \mathrm{dt}=\mathrm{f}(-\mathrm{m})$ \\
\hline NCCHf & 14.1 & 3.87 & 12.0 & 86.6 \\
\hline NCC (for comparison) & 17.8 & 5.80 & 14.3 & 71.7 \\
\hline
\end{tabular}

Before cross-section preparation the two oxidized samples were photographed and subjected to Xray diffraction. The two types of results are given together in Fig. 4. NCC obviously suffered scale spallation during the $-5^{\circ} \mathrm{C} \mathrm{min}^{-1}$ cooling after the isothermal oxidation, while NCCHf has obviously kept all its external scale. The X-ray diffractograms show that, even if $\mathrm{Cr}_{2} \mathrm{O}_{3}$ is the main oxide present in both cases, the scales formed over NCC contain significant parts of spinel $\mathrm{NiCr}_{2} \mathrm{O}_{4}$ and even $\mathrm{NiO}$. In addition the substrate (Ni-Cr austenitic alloy) is also more detected in its case than for NCCHf, consequently to its more extended oxide spallation. The external oxide scale formed around $\mathrm{NCCHf}$ is richer in chromia than $\mathrm{NCC}$, but it contains a little spinel $\mathrm{NiCr}_{2} \mathrm{O}_{4}$ and also the hafnium oxide.

The cross-sectional examinations (Fig. 5, NCCHf surface and subsurface with two magnifications) confirm these observations. Additionally one can see that no carbide-free zone developed from the oxidealloy interface, in contrast with what generally occurs for cast $\mathrm{Ni}$ alloys with chromium carbides or $\mathrm{TaC}$ carbides. Indeed, the HfC carbides seem being still present in alloy close to the external oxide. X-ray diffraction and cross-sectional EDS spot analysis show that the carbides close to the oxide/alloy interface are oxidized in situ: $\mathrm{HfC}$ are replaced by $\mathrm{HfO}_{2}$ at the same location. 

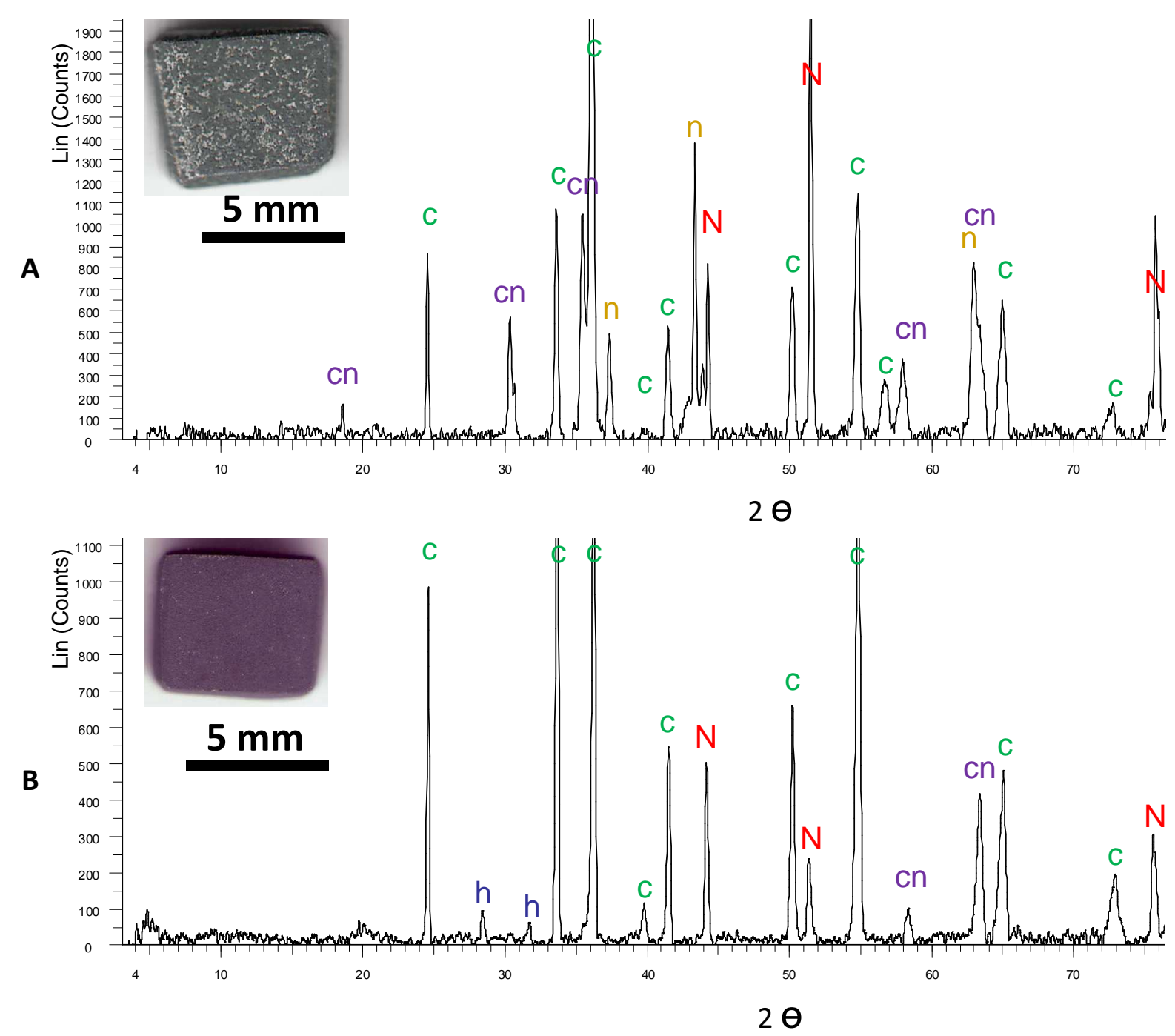

Fig. 4. NCC (A) and NCCHf (B) oxidized at $1100^{\circ} \mathrm{C}$ for $46 \mathrm{~h}$ : the X-ray diffractograms obtained on the oxidized surfaces ("c": $\mathrm{Cr}_{2} \mathrm{O}_{3}$, "cn: $\mathrm{NiCr}_{2} \mathrm{O}_{4}$, "n": $\mathrm{NiO}$, "N": $\mathrm{FCC}$ Ni-based matrix); visualization of the oxide spallation (photographs in the top-right corners)

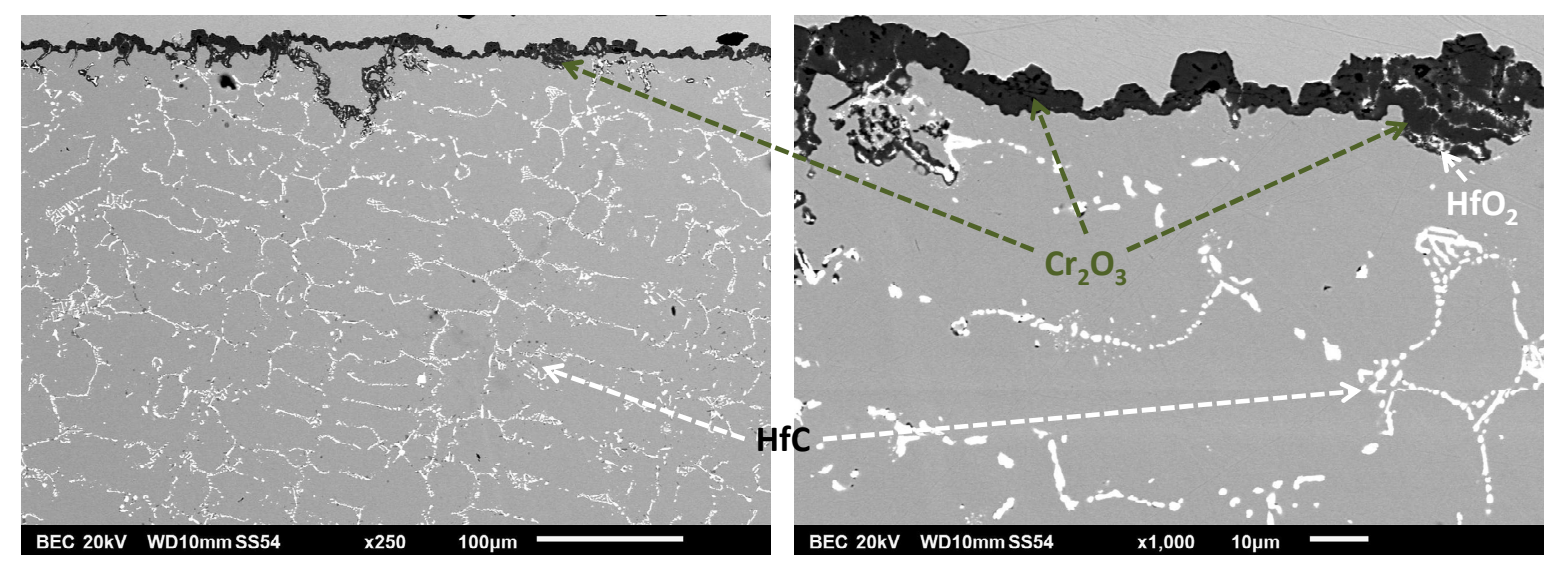

Fig. 5. Cross-sectional observations of the oxidized surface and subsurface of the NCCHf sample (left: general view, right: detailed view) 


\section{Conclusion}

The studied alloy demonstrated very interesting properties: rather high level of hardness but still compatible with a sufficient machinability, good creep resistance at $1100^{\circ} \mathrm{C}$ for a resulting tensile stress of $20 \mathrm{MPa}$ and very good oxidation behavior. Concerning the two first points the high hardness of the HfC carbides (harder than $\mathrm{Cr}_{7} \mathrm{C}_{3}$ and $\mathrm{Cr}_{23} \mathrm{C}_{6}$ ) and their stability at H.T. bring important advantages by comparison with other more classical carbides. Concerning the last point this is essentially the Ni-base matrix which brings its intrinsic good high temperature behavior (by comparison with Co-based alloys for example). But the second beneficial role of $\mathrm{Hf}$ here, which is usually the main one in many cases, was also observed: the improvement in oxide scale adherence and thus resistance against spallation. Workable by foundry and offering so high levels of mechanical and chemical properties at H.T., this alloy ought to meet needs in structural metallic alloys for many high temperature applications.

\section{Acknowledgments}

The authors wish to thank Th. Schweitzer and P. Villeger for their help.

\section{References}

1. Lund C. H. and Hockin J. Investment casing / Eds. C. T. Sims and W. C. Hagel // The Superalloys. New York: John Wiley and Sons, 1972. - P. 423-425.

2. Berthod P., Aranda, L. Vébert C. and Michon S. Experimental and thermodynamic study of the microstructural state at high temperature of nickel base alloys containing tantalum // Calphad. - 2004. - 28, № 2. - P. 159-166.

3. Berthod $P$. High temperature properties of several chromium-containing Co-based alloys reinforced by different types of MC carbides ( $\mathrm{M}=\mathrm{Ta}, \mathrm{Nb}, \mathrm{Hf}$ and/or $\mathrm{Zr}$ ) // Journal of Alloys and Compounds. - 2009. 481. - P. 746-754.

4. Berthod P. and Conrath E. Microstructure evolution in the bulk and surface states of chromium-rich nickel-based cast alloys reinforced by hafnium carbides after exposure to high temperature in air //

Materials at High Temperature. - 2014. - 31, № 3. - P. 266-273.

5. Berthod $P$. Kinetics of high temperature oxidation and chromia volatilization for a binary Ni-Cr alloy // Oxidation of Metals. - 2005. - 64, № 3-4. - P. 235-252. 